\title{
Bases teórico-metodológicas para a elaboração de um dicionário português-espanhol de Economia
}

\author{
Odair Luiz Nadin*
}

\begin{abstract}
The aim of this article is to present the theoretic-methodological bases for the construction of a bilingual terminological dictionary of economics which serves either Portuguese and Spanish speakers. The contrasted languages are the Brazilian Portuguese variety and the peninsular and Argentinean varieties. The purpose of this text is based on the principles of the Communicative Theory of Terminology - CTT (Cabré, 1999).
\end{abstract}

Keywords: Bilingual terminological dictionary, Terminology, Terminography, Communicative Theory of Terminology.

Resumo: Temos por objetivo, neste artigo, apresentar as bases teórico-metodológicas para a elaboração de um dicionário terminológico bilíngue de Economia que possa atender tanto aos falantes da língua de partida, quanto aos falantes da língua de chegada. As línguas contrastadas são o português na variedade brasileira e o espanhol nas variedades peninsular e argentina. A proposta delineada neste texto se fundamenta nos princípios da Teoria Comunicativa da Terminologia - TCT (CABRÉ, 1999).

Palavras-chave: Dicionário Terminológico Bilíngue - Terminologia - Terminografia Teoria Comunicativa da Terminologia.

\footnotetext{
* Professor Assistente Doutor do Departamento de Letras Modernas da Faculdade de Ciências e Letras/ Universidade Estadual Paulista "Júlio de Mesquita Filho" - UNESP/Araraquara. Email: odair.lluiz@gmail.com.
} 


\section{Introdução}

O processo teórico-metodológico de elaboração de dicionários, seja da língua comum ou terminológico, deve partir do delineamento do perfil dos possíveis usuários e da função ou funções que o dicionário deverá cumprir para esses usuários.

As bases teórico-metodológicas que descrevemos neste artigo estão pensadas para a elaboração de dicionários terminológicos bilíngues cujos possíveis usuários sejam falantes de português ou de espanhol envolvidos com o domínio da Economia. Dentre as muitas subáreas da Economia, escolhemos para propor o dicionário da Economia Monetária. Desse modo, pudemos descrever e explicar, a partir de um âmbito especializado mais bem definido, a metodologia usada em nossa proposta.

A proposta que ora apresentamos se enquadra nos princípios defendidos pela Teoria Comunicativa da Terminologia - TCT (CABRÉ 1999) e busca, nessa teoria, subsídios que sustentem um modelo de dicionário que possa atender aos falantes das línguas descritas que são, nesse caso, o português na variedade brasileira e o espanhol nas variedades peninsular e argentina.

Assim, a partir dos pressupostos teóricos da TCT e da metodologia utilizada, buscamos elaborar uma proposta que se concretiza, na verdade, em dois dicionários, ou seja, um dicionário na direção português-espanhol e outro na direção espanhol-português.

Cada um desses dicionários poderá, no modelo apresentado, desempenhar uma dupla função. Por um lado, o dicionário portuguêsespanhol poderá auxiliar o falante de português na produção de textos em espanhol (dicionário ativo) e o falante de espanhol na compreensão de textos em português (dicionário passivo). Por outro lado, o dicionário espanholportuguês poderá auxiliar o falante de português na compreensão de textos em espanhol e o falante de espanhol na produção de textos em português. 
Defendemos que essa dupla função de cada dicionário é possível porque partimos do perfil dos usuários em potencial da obra e por se tratar de dicionários terminológicos, ou seja, os usuários que possivelmente os utilizarão são aprendizes ou profissionais imersos no contexto econômicofinanceiro.

Organizamos, assim, o presente artigo em três partes: na primeira, discorremos brevemente sobre o Princípio de Adequação proposto pela Teoria Comunicativa da Terminologia (CABRÉ 1999) e as implicações desse Princípio ao trabalho terminográfico. Na segunda parte, descrevemos o processo metodológico de elaboração da proposta de dicionário para, na terceira e última parte, propor uma estrutura de dicionário terminológico bilíngue que possa ser útil aos falantes das línguas nele descritas.

\section{A Teoria Comunicativa da Terminologia e o Princípio de Adequação}

Entre as inovações teórico-metodológicas que a TCT proporcionou aos estudos terminológicos destacam-se, também, significativas transformações na metodologia de elaboração de dicionários especializados. Essa transformação se dá, sobretudo, a partir do Princípio de Adequação.

Um trabalho terminográfico, com base na TCT, além de respeitar os fundamentos da teoria, deve adequar-se em função de alguns fatores, como 0 tema da pesquisa, o contexto, os usuários do produto final, entre outros aspectos, como podemos apreender das palavras de CABRÉ:

A ideia central da metodologia da TCT é a de adequação. Essa teoria propõe uma metodologia ampla que reflete os pressupostos gerais da metodologia de todo trabalho terminológico e os fundamentos obrigatórios da TCT. Esta metodologia serve de marco restritivo para a atividade prática. Com exceção dos princípios mínimos que Ihe servem de marco, cada trabalho em concreto adota uma estratégia em função 
de sua temática, contexto, elementos implicados e recursos disponíveis. Nessa teoria, pois, em vez de se impor a metodologia, esta se adapta à circunstância sem contradizer os princípios: a adequação metodológica está acima da unificação extrema. Assim, um trabalho pode adotar uma perspectiva onomasiológica ou semasiológica; pode partir de textos ou de bancos de dados; pode processar automaticamente textos em suporte digitalizado e aplicar detectores automáticos que exigem um minucioso trabalho de supervisão; podem propor a normalização dos termos de uma matéria ou simplesmente recopilar os usos efetivos que os especialistas implicados fazem deles. Em todos os casos se respeitarão os princípios mínimos, mas cada um adequará a metodologia às suas circunstâncias. ${ }^{1}$ (CABRÉ 1999: 137).

O Princípio de Adequação é, portanto, para a TCT, a chave do trabalho terminológico que reflete, evidentemente, no trabalho terminográfico. Segundo o tema que se pesquise e os usuários que se pretenda atender, o trabalho se organizará de forma distinta. LORENTE (2001: 99) desenvolve algumas reflexões sobre este princípio e esclarece "que o fato de que a aproximação da TCT à terminologia seja linguística, as aplicações terminográficas que se defendem nessa teoria apresentam algumas variáveis".

Segundo a autora, para a elaboração de um dicionário terminológico à luz da proposta teórica da TCT, faz-se necessário considerar dois fatores: (i) as funções lexicográficas e (ii) os usuários e suas necessidades. Sobre as funções do dicionário, ainda segundo a autora, "a obra pode ter um caráter didático, descritivo, corretivo, prescritivo, etc". (2001: 99) Sobre os usuários e suas necessidades, um dicionário terminológico pode atender aos aprendizes e professores de uma dada disciplina, aos documentalistas, tradutores, intérpretes, redatores, entre outros.

Em suma, as orientações teórico-metodológicas para o trabalho terminográfico, embasadas nos princípios da TCT, são, segundo LORENTE, as seguintes:

\footnotetext{
${ }^{1}$ Realizamos esta e as demais traduções presentes neste artigo.
} 
- a terminografia atual aparece como um setor de aplicação aberto que inclui desde os clássicos modelos de vocabulários especializados de orientação prescritiva até as manifestações que foram consideradas fora da terminografia estrita, como os dicionários técnicos e os enciclopédicos.

- A diversidade de produtos terminográficos é condicionada pelas necessidades dos usuários e pelas finalidades para as quais os dicionários estão desenhados.

- A terminografia pode apresentar, como a lexicografia, uma diversidade de funções: descritiva, prescritiva, corretiva ou didática.

A consideração da autora justifica nossa proposta de dicionário terminológico bilíngue no par de línguas português/ espanhol que possa servir tanto ao falante de português quanto ao falante de espanhol. A delimitação do usuário e da função do dicionário vincula-se, nesse caso, ao âmbito de conhecimento no qual estão inseridos esses falantes, ou seja, a Economia. Na era da Globalização, em que profissionais falantes de português ou de espanhol atuam tanto no Brasil quanto nos países hispânicos, não seria pertinente um dicionário que atendesse somente o falante de uma das línguas envolvidas.

\section{Metodologia:}

\subsection{Delineando o perfil dos possíveis usuários dos dicionários}

O usuário prototípico dos dicionários terminológicos que propomos são os diferentes profissionais e/ ou aprendizes envolvidos na área da Economia Monetária e áreas correlatas. Por questões metodológicas, classificamos esses possíveis usuários em três grupos: 
- Docentes ou aprendizes: professores ou estudantes de graduação ou pós-graduação em Economia ou áreas afins.

- Especialistas em Economia e/ou demais profissionais que atuam em relações comerciais, econômicas e/ ou bancárias entre Brasil, Espanha e Argentina.

- Profissionais de outras áreas (brasileiros, espanhóis e argentinos) em interação com falantes de português ou espanhol ou com textos escritos nessas línguas no âmbito da Economia Monetária (tradutores, revisores, profissionais de comércio exterior, secretários executivos etc.).

Esses diferentes profissionais possuem atribuições que, de alguma forma, os colocam em interação com a área da Economia Monetária. Nessa interação, as línguas portuguesa ou espanhola, como língua materna ou estrangeira, cumprem relevante função. Embora esses profissionais se acerquem à língua estrangeira a partir de perspectivas diferentes, possuem a necessidade comum de entender dados veiculados nessas línguas para compreender, produzir ou traduzir textos.

No caso de profissionais que atuam diretamente com falantes de outra língua ou como mediadores no processo comunicativo, o dicionário que propomos pode ajudá-los na compreensão do uso especializado da língua no âmbito econômico-financeiro.

0 crescimento das relações comerciais, econômicas e culturais entre 0 Brasil e os países de língua espanhola nos últimos anos, sobretudo a partir da última década do século $X X$, beneficiou outras áreas que têm passado por um processo de desenvolvimento. Entre essas áreas, destacam-se a Tradução, 0 Comércio Exterior e o Secretariado Executivo.

Para os tradutores, os dicionários bilíngues são ferramentas de uso diário. No caso dos profissionais de Comércio Exterior e os Secretários Executivos, apesar da perspectiva de uso da língua ser outra, um dicionário 
bilíngue de Economia pode ser também bastante útil. Esses profissionais atuam tanto nas relações diretas entre empresas brasileiras e estrangeiras, como também em organização de feiras e eventos comerciais e culturais entre diferentes países.

Apresentamos, no quadro abaixo, síntese dos perfis dos usuários e dos tipos de dicionários que, a partir do ponto de vista adotado nessa pesquisa, poderia atendê-los.

\begin{tabular}{|c|c|c|c|c|}
\hline $\begin{array}{l}\text { Qual é a } \\
\text { língua } \\
\text { materna dos } \\
\text { possíveis } \\
\text { usuários? }\end{array}$ & $\begin{array}{c}\text { Que } \\
\text { necessidades os } \\
\text { usuários } \\
\text { possuem? }\end{array}$ & $\begin{array}{c}\text { Que } \\
\text { informações os } \\
\text { usuários } \\
\text { buscam e como } \\
\text { as encontram? }\end{array}$ & $\begin{array}{c}\text { Em que tipo de } \\
\text { dicionário os } \\
\text { usuários } \\
\text { buscam as } \\
\text { informações } \\
\text { que precisam? }\end{array}$ & $\begin{array}{c}\text { Tipo de } \\
\text { dicionário }\end{array}$ \\
\hline $\begin{array}{l}\text { Falantes de } \\
\text { espanhol }\end{array}$ & $\begin{array}{l}\text { Precisam saber } \\
\text { como se } \\
\text { denomina em } \\
\text { português o que } \\
\text { se denomina " } x \text { " } \\
\text { em espanhol. }\end{array}$ & $\begin{array}{c}\text { Buscam o lema } \\
\text { espanhol e } \\
\text { encontram o } \\
\text { lema } \\
\text { equivalente em } \\
\text { português. }\end{array}$ & $\begin{array}{l}\text { Em um } \\
\text { dicionário } \\
\text { espanhol- } \\
\text { português }\end{array}$ & $\begin{array}{c}\text { Dicionário } \\
\text { para produção } \\
\text { (dicionário } \\
\text { ativo) }\end{array}$ \\
\hline $\begin{array}{c}\text { Falantes de } \\
\text { português }\end{array}$ & $\begin{array}{l}\text { Precisam saber } \\
\text { como se } \\
\text { denomina em } \\
\text { espanhol o que } \\
\text { se denomina "y" } \\
\text { em português. }\end{array}$ & $\begin{array}{l}\text { Buscam o lema } \\
\text { em português e } \\
\text { encontram o } \\
\text { equivalente em } \\
\text { espanhol. }\end{array}$ & $\begin{array}{l}\text { Em um } \\
\text { dicionário } \\
\text { português- } \\
\text { espanhol }\end{array}$ & $\begin{array}{c}\text { Dicionário } \\
\text { para produção } \\
\text { (dicionário } \\
\text { ativo) }\end{array}$ \\
\hline $\begin{array}{c}\text { Falantes de } \\
\text { espanhol }\end{array}$ & $\begin{array}{l}\text { Precisam saber } \\
\text { o que significa o } \\
\text { lema que leem } \\
\text { em português. }\end{array}$ & $\begin{array}{l}\text { Buscam no } \\
\text { dicionário } \\
\text { português- } \\
\text { espanhol e } \\
\text { encontram o } \\
\text { equivalente } \\
\text { mais a definição } \\
\text { em espanhol. }\end{array}$ & $\begin{array}{l}\text { Em um } \\
\text { dicionário } \\
\text { português- } \\
\text { espanhol }\end{array}$ & $\begin{array}{l}\text { Dicionário } \\
\text { para } \\
\text { compreensão } \\
\text { (dicionário } \\
\text { passivo) }\end{array}$ \\
\hline $\begin{array}{c}\text { Falantes de } \\
\text { português }\end{array}$ & $\begin{array}{l}\text { Precisam saber } \\
\text { o que significa o } \\
\text { lema que leem } \\
\text { em espanhol. }\end{array}$ & $\begin{array}{l}\text { Buscam no } \\
\text { dicionário } \\
\text { espanhol- } \\
\text { português e } \\
\text { encontram o } \\
\text { equivalente } \\
\text { mais a definição } \\
\text { em português. }\end{array}$ & $\begin{array}{l}\text { Dicionário } \\
\text { espanhol- } \\
\text { português }\end{array}$ & $\begin{array}{l}\text { Dicionário } \\
\text { para } \\
\text { compreensão } \\
\text { (dicionário } \\
\text { passivo) }\end{array}$ \\
\hline
\end{tabular}

Quadro 1: Perfis de usuários e de necessidades 
Cada um dos dicionários em questão cumpre, assim, uma dupla função, ou seja, serve à produção ou à compreensão de textos em língua estrangeira. Essa função varia segundo a língua materna do usuário.

A partir, pois, dessas características de usuários, de necessidades e de tipos de dicionários, propomos um dicionário que pode contribuir à comunicação entre falantes de português e falantes de espanhol, sobretudo brasileiros, argentinos e espanhóis, no domínio econômico-financeiro. No item seguinte, descrevemos a metodologia de organização dos corpora utilizados.

\subsection{A organização dos corpora}

Para esse trabalho, isto é, a organização e a manipulação dos corpora, usamos, além das teorias e técnicas da Terminologia e da Terminografia, a contribuição da Linguística de Corpus.

[...] a Linguística de Corpus ocupa-se da coleta e exploração de corpora, ou conjuntos de dados linguísticos textuais que foram coletados criteriosamente com o propósito de servirem para a pesquisa de uma língua ou variedade linguística. Como tal, dedica-se à exploração da linguagem através de evidências empíricas, extraídas por meio de computador. (SARDINHA 2000: 325).

O autor acrescenta que, apesar da relevância da Linguística de Corpus aos estudos da linguagem, ela é ainda bastante incipiente no Brasil (2000: 329). Trata-se, portanto, de uma metodologia que se dedica à organização de bases de dados escritos e/ ou orais de muitas variedades linguísticas ou de algum recorte em especial denominada corpus. Por corpus se compreende "um corpo de linguagem natural (autêntica) que pode ser usado como base para pesquisa linguística". (SINCLAIR 1991: 171).

Biderman (2001: 79) esclarece que um corpus é um "conjunto homogêneo de amostras da língua de qualquer tipo (orais, escritos, literários, coloquiais etc.). Tais amostras são escolhidas como modelo de um estado ou 
nível de língua predeterminado". Ainda segundo a autora, "a análise dos dados linguísticos de um corpus deve permitir ampliar o conhecimento das estruturas linguísticas da língua que eles representam".

A autora também se refere à questão do corpus linguístico informatizado. Para ela, esse corpus é "uma coletânea de textos selecionados segundo critérios linguísticos, codificados de modo padronizado e homogêneo e tratado mediante processos informáticos". (BIDERMAN 2001: 79).

Os corpora textuais que serviram à extração das Unidades Terminológicas (doravante UTs) e à elaboração da proposta de dicionário apresentados nessa pesquisa foram constituídos de textos escritos selecionados de sites oficiais de bancos públicos e privados, de instituições financeiras, de revistas, jornais e livros referentes ao âmbito da Economia Monetária.

Organizou-se um corpus formado por textos em língua portuguesa (variedade brasileira) e outro, dividido em duas partes, formado por textos em língua espanhola. A primeira parte do corpus em espanhol contempla textos na variedade peninsular e, a segunda, textos na variedade argentina. Em todos os casos, seguimos os mesmos critérios de seleção e organização.

O corpus referente ao Português Brasileiro (PB) foi organizado pela Profa. Dra. Maria Tereza Camargo Biderman (BIDerman, 2003) e integrado ao acervo informatizado do Centro de Estudos Lexicográficos da UNESP, campus de Araraquara. As fontes que serviram à extração dos textos foram classificadas em seis blocos:

\begin{tabular}{|c|l||}
\hline Bloco & \multicolumn{1}{|c|}{ Fontes dos textos } \\
\hline 01 & Associações Financeiras \\
\hline \hline 02 & Bancos e Bolsas de Valores \\
\hline \hline 03 & J ornalismo (fonte internet) \\
\hline \hline 04 & Livros \\
\hline \hline 05 & Revistas especializadas \\
\hline \hline 06 & Sites de Economia \\
\hline
\end{tabular}

Quadro 2: Classificação das fontes dos textos que compõem os corpora 
Entre as Associações Financeiras do Brasil das quais os textos foram compilados destacam-se a Federação Brasileira dos Bancos (FEBRABAN), a Associação Brasileira dos Analistas do Mercado de Capitais (ABAMEC) e a Associação Nacional de Investidores do Mercado de Capitais (ANIMEC).

Entre os Bancos e Bolsas de Valores, foram considerados textos dos sites do Banco Central do Brasil, Banco do Brasil, Santander/Banespa, Unibanco, Bolsa de Valores de São Paulo (Bovespa) e Bolsa de Mercadoria e Futuros. Além disso, foram selecionados textos de jornais (por meio da internet), como a Gazeta Mercantil, Valor.com e 0 Estado de São Paulo, bem como sites especializados em Economia como, por exemplo, o UOL online, rede globo.com, puc-rio.br, risktech.com. br e portalexame. abril. uol.com.br.

Quanto aos livros, foram selecionados os que estão, em geral, nas referências bibliográficas de programas de graduação e pós-graduação em Economia, entre os quais destacamos:

FORTUNA, E. Mercado financeiro: produtos e serviços. 15. ed. Rio de Janeiro: Qualitymark, 2002.

BALEEIRO, A. Uma Introdução à ciência das finanças. Rio de J aneiro: Forense, 2002.

LAmelRA, V. Mercado de Capitais. Rio de J aneiro: Forense, 2001.

ReZendE, F. A. Finanças Públicas. 2. ed. São Paulo: Atlas, 2001.

Todas essas fontes apresentam, em diferentes níveis de especialização, unidades léxicas da língua portuguesa em contextos reais de uso no âmbito da Economia. Seguindo os critérios metodológicos utilizados para a constituição do corpus do PB (BIDERMAN 2003), organizamos um corpus de língua espanhola, considerando as duas variedades mencionadas (peninsular e argentina).

O corpus da língua espanhola foi organizado, portanto, a partir de textos escritos, de diferentes gêneros e veículos de divulgação. Entre as Associações, tomamos, por exemplo, textos da Asociación de Bancos de la República Argentina (ABA) e do Centro de Estudios de la Estructura Económica (CENES), ambas instituições argentinas. Entre os bancos e bolsas 
de valores, destacamos o Banco Central Europeo, o Banco Central de España, - Banco Bilbao Vizcaya Argentaria S.A., a Bolsa de Barcelona (referentes à Espanha) e o Banco Central de la República Argentina - BCRA, o Banco de la Provincia de Buenos Aires, a Bolsa de Comercio de Buenos Aires (referentes à Argentina).

Foram coletados textos, ainda, de revistas especializadas, como as Revistas Institucional Bolsa de Rosário da Argentina e a Estabilidad Financiera, vinculada ao Banco Central da Espanha. Faz parte, também, do corpus em espanhol alguns livros disponíveis em sites argentinos e europeus, dos quais destacamos:

Granato, L. Protección del inversor extranjero y arbitraje internacional en los Tratados Bilaterales de Inversión. Facultad de Derecho y Ciencias Sociales. Universidad de Belgrano, Argentina. 2005. Disponível em: «tttp:// www. eumed. net/ libros/ 2005/ lg/ >. (13/ 10/ 2005).

VIRGILE, A. ¿Ahorrar para acumular o para financiar la crisis? Una aproximación a sesenta y cinco años de ahorro privado en Argentina. Disponível em: «ttp:// www. eumed. net/ cursecon/ libreria/ >. 2004. (20/1/2005).

ODONNE, C. N. Mercados Emergentes y Crisis Financiera Internacional. Disponível em: \ttml:// www. eumed. net/ cursecon/ libreria/ >. 2004. (20/1/2005).

Ambos os corpora (português e espanhol) estão constituídos de, aproximadamente, um milhão e duzentas mil palavras cada. Esse número é dividido em quantidades aproximadas entre os seis diferentes blocos apresentados antes no quadro 2.

A inclusão nos corpora de textos veiculados nos cadernos de Economia dos principais jornais dos países em questão (El País-Espanha, El ClarínArgentina e a Folha de São Paulo-Brasil) se fundamenta, sobretudo, em HAENSCH et al. (1982: 138). Os autores afirmam que:

[...] para coletar um vocabulário de atualidade política, econômica ou cultural é recomendável a leitura paralela de bons jornais. Desse modo, artigos sobre o lançamento de uma nave espacial ou sobre as eleições presidenciais nos Estados Unidos, por exemplo, publicados em jornais espanhóis e hispano-americanos do mesmo dia, trarão um rico e variado vocabulário, tudo no mesmo contexto (HAENSCH et al.1982: 138). 
Além disso, salientamos que essa inclusão se justifica, ainda, pelo fato de que compartilhamos a tese de diferentes níveis de especialidade desses textos. Evidentemente que observamos, ao selecioná-los, algumas questões relativas aos autores como a formação acadêmica, a área de atuação, as atividades profissionais exercidas por eles, entre outras.

HAENSCH et al. (1982: 138) observam, também, que "o vocabulário técnico não se limita a determinadas profissões ou grupos; ao contrário, uma das características das línguas modernas é precisamente 0 fato dos termos técnicos migrarem para a língua comum". Os autores ressaltam a questão da variação diatópica e afirmam que "um dicionário de termos da Economia, do comércio ou financeiros que considere somente o uso peninsular não atenderá satisfatoriamente a um usuário hispano-americano". ${ }^{2}$

\subsection{A seleção das Unidades Terminológicas}

Recorremos, inicialmente, aos manuais de Economia em português (ForTunA, 2002; LOPES; RosSetI, 1996; BaleEIRO, 2002 etc.) presentes nas referências bibliográficas de curso de graduação e pós-graduação. A partir das consultas aos manuais, iniciamos o processo de elaboração da estrutura conceitual.

(i) Moeda; (ii) Política Monetária; (iii) Inflação e (iv) Sistema Financeiro.

\footnotetext{
${ }^{2}$ Esse aspecto está contemplado em nossa proposta à medida que abordamos as variedades peninsular e argentina do espanhol. Entretanto, reconhecemos a importância dos outros países membros do Mercosul, bem como dos demais países hispano-americanos e de suas variedades linguísticas. Em virtude das limitações de espaço e tempo que nos são impostas para este tipo de trabalho, optamos por considerar, para nossa pesquisa, as variedades referentes à Espanha e à Argentina. Encontra-se, em andamento, outro projeto de pesquisa sob nossa coordenação que pretende contemplar as variedades linguísticas dos países hispânicos do Mercosul no domínio da Economia.
} 
A partir dessa divisão e, ainda com base nos manuais de Economia supramencionados, organizamos uma primeira versão de estrutura conceitual da Economia Monetária. A elaboração dessa proposta em língua portuguesa se justifica pelo fato de que, como falante nativo desse idioma e não especialista na área da Economia, nos proporcionou uma aproximação mais segura às relações de significado entre as UTs abordadas. Ademais, a elaboração dessa estrutura foi bastante relevante ao reconhecimento das UTs no espanhol em relação de equivalência com o português.

Apresentamos, abaixo, a representação da primeira fase de organização da subárea da Economia Monetária. Nessa proposta de organograma, procuramos identificar, primeiramente, a macroestrutura dessa subárea da Economia.

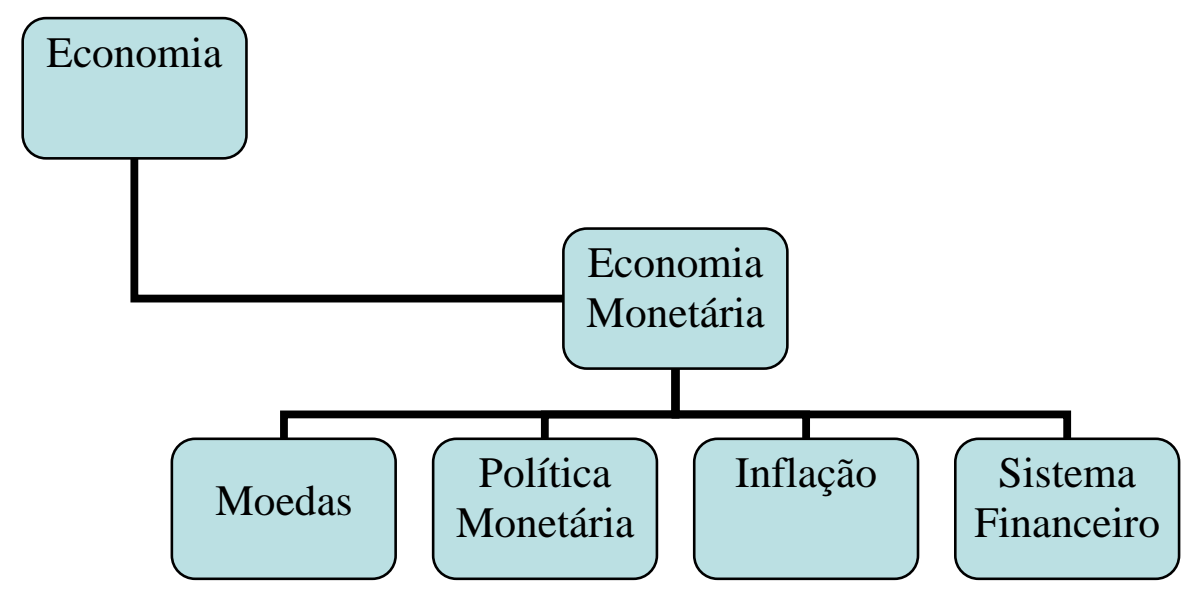

Figura 1: Proposta de organograma de Economia Monetária: primeira fase

Desse modo, cada um dos quatro segmentos da Economia Monetária que apresentamos (Moeda; Política Monetária, Inflação e Sistema Financeiro) se desdobra em alguns outros, conforme exemplo abaixo (figura 2): 


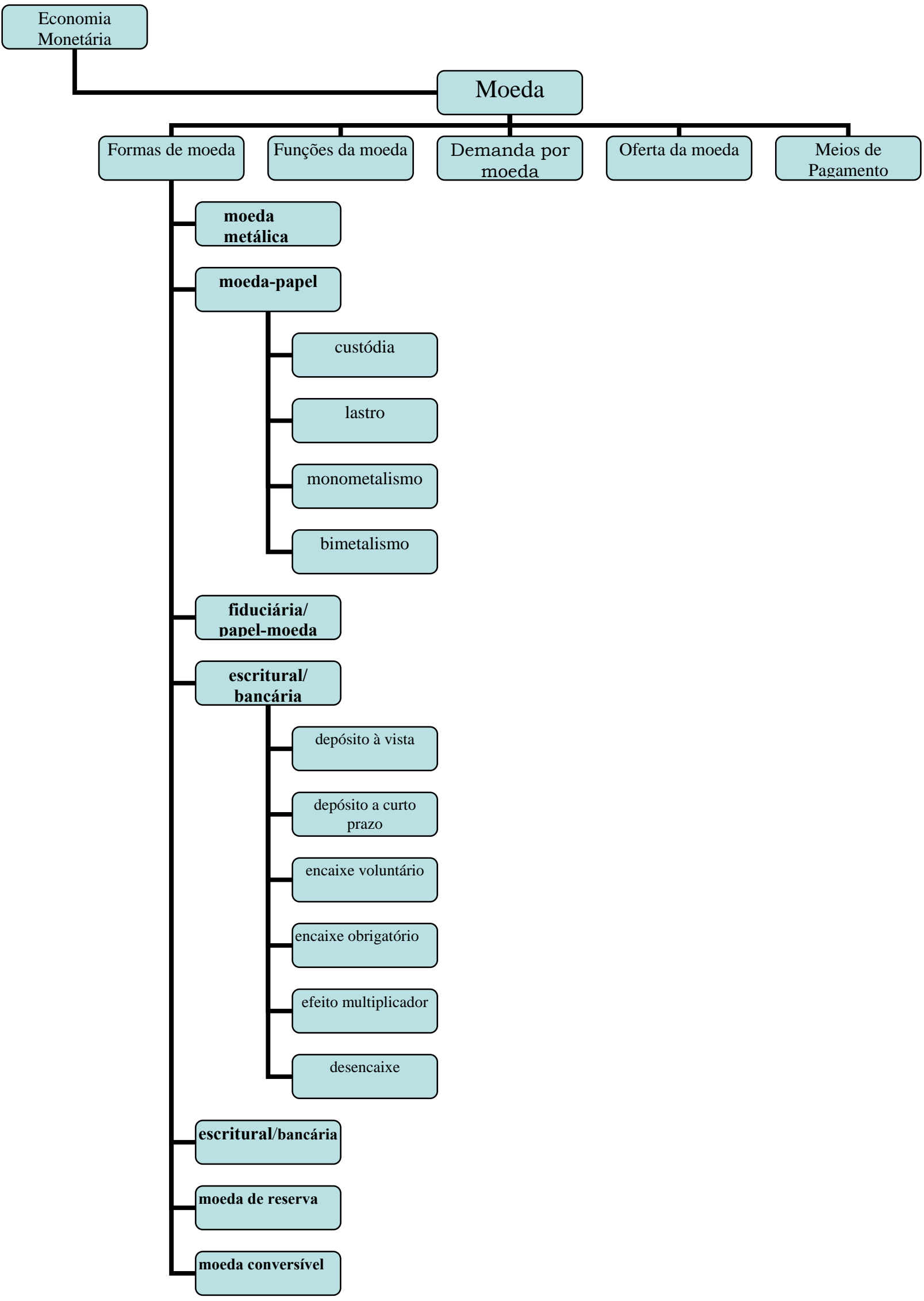

Figura 2: Exemplo resumido da estrutura conceitual proposta 
A partir dessa estrutura conceitual em português, selecionamos do corpus da língua espanhola, aproximadamente, mil candidatos a termos. Buscamos identificar nessa lista quais unidades se repetiam nos contextos peninsular e argentino, a fim de verificar possibilidades de variação denominativa entre as duas variedades do espanhol.

Com a proposta de estrutura conceitual em língua portuguesa e a lista de candidatos a termos extraída do corpus do espanhol, iniciamos o processo de identificação das unidades em possível relação de equivalência entre as duas línguas.

CANo (2001: 90) afirma que "a tarefa de selecionar e organizar unidades terminológicas para a elaboração de um produto terminográfico requer decisões sobre problemas ainda escorregadios". Segundo a autora, é necessário:

(i) o estabelecimento de critérios para se determinar se uma unidade é ou não terminológica (critério de especificidade temática);

(ii) saber se as unidades consideradas terminológicas são próprias ou não de um campo especializado (critério de atribuição de âmbito);

(iii) estabelecer os critérios que permitem determinar se as unidades que aparecem nos textos são ou não pertinentes para determinado vocabulário (critério da pertinência);

(iv) a delimitação do segmento formal que corresponde a uma unidade especializada, isto é, precisar qual sua forma linguística (critério de delimitação).

Para cumprir esses critérios, é preciso identificar as possíveis UTs em contextos de uso, ou seja, em corpora textuais próprios do âmbito do conhecimento a ser estudado. Desse modo, haja vista que partimos de textos do âmbito da Economia Monetária e contamos com assessores profissionais nessa área do conhecimento, as UTs descritas e analisadas cumprem os critérios estabelecidos.

Consideramos, assim, para a seleção das UTs as seguintes etapas: 
(i) organizamos uma proposta de estrutura conceitual em língua portuguesa com base em manuais de Economia e programas da disciplina de Economia Monetária em nível de graduação e pósgraduação;

(ii) selecionamos candidatos a UT do corpus da língua espanhola nas duas variedades da língua contempladas na pesquisa;

(iii) realizamos uma primeira aproximação ao fenômeno da variação entre as variedades peninsular e argentina do espanhol;

(iv) identificamos as UTs em possível relação de equivalência entre as duas línguas ou entre as duas variedades do espanhol.

De posse dessa lista inicial de supostos equivalentes nas duas línguas em questão, buscamos contextos mais precisos para a confirmação das equivalências e elaboração das fichas terminológicas. Os dados contidos nas fichas nos serviram à descrição e análise, bem como à composição da nomenclatura do dicionário-piloto e à redação dos verbetes.

\section{A macro e a microestrutura: uma proposta}

Um dicionário pode se propor a atender diferentes tipos de usuários simultaneamente e servir a uma ou mais funções. A organização da estrutura da obra dependerá, portanto, das decisões prévias sobre o usuário e as funções do dicionário.

Assim, um dicionário bilíngue pode apresentar-se nas seguintes estruturas:

(i) monofocal: nesse caso, o dicionário é elaborado seguindo princípios que consideram um tipo específico de usuário e de função (compreensão ou produção); 
(ii) bifocal: nesse caso, além de considerar o usuário e a função do dicionário, que são dois aspectos fundamentais, considera-se, também, questões relativas à praticidade da obra.

Gelpí observa que:

O dicionário bilíngue, com a representação genérica, responde a uma estrutura textual determinada que se desenvolve, no mínimo, em três níveis que são a superestrutura, a macroestrutura e a microestrutura. A superestrutura compreende a organização geral das informações da obra, considerando as unidades das duas línguas e as informações sobre as duas línguas. A macroestrutura é formada pelo conjunto das entradas selecionadas para a nomenclatura e abrange a seleção, a representação e a ordem como aparecem na obra. E a microestrutura é formada pelo conjunto das informações organizadas em cada verbete. (Gelpi 1997: 110. Grifo nosso).

Como propomos organizar os dicionários em um só volume, faz-se necessária a inclusão de um nível a mais na estrutura proposta por Gelpí (1997), o que denominamos aqui, por questões metodológicas, de megaestrutura. A megaestrutura é composta, portanto, por:

(i) Introdução: texto introdutório cuja função é apresentar o conjunto total do dicionário e dar ao usuário as orientações de uso da obra. Por essa razão, as informações que figuram na introdução são redigidas nas duas línguas em questão.

(ii) Superestrutura bifocal 1: composta pela macro e pela microestrutura na direção português-espanhol.

(iii) Apêndice I: informações sobre as principais instituiçoes financeiras do Brasil.

(iv) Superestrutura bifocal 2: composta pela macro e pela microestrutura na direção espanhol-português.

(v) Apêndice II: informações sobre as principais instituiçoes financeiras da Espanha e da Argentina. 
As discussões apresentadas acima com base nos autores citados, com as devidas adequações à presente pesquisa, corroboram nossa proposta de dicionário. Propomos, assim, um dicionário bilíngue bidirecional e bifuncional. Salientamos que parte da estrutura aqui apresentada, adaptamo-na de Gelpí (1997: 113).

O dicionário terminológico bilíngue proposto possui, portanto, as seguintes características:

parte de uma descrição in vivo (CABRÉ 1999) das unidades léxicas de valor especializado em ambas as línguas que compõem as macroestruturas;

> é elaborado a partir de um perfil devidamente delineado de possíveis usuários e de suas necessidades;

> propõe-se, com base no Princípio de Adequação defendido pela TCT, servir às funções de produção e de compreensão de textos em espanhol ou português no âmbito da Economia Monetária.

apresenta informações sobre as principais Instituições que compõem os sistemas financeiros dos três países em questão, o que facilita 0 trabalho dos profissionais da área bem como dos aprendizes.

No item seguinte, apresentamos a organização da microestrutura do dicionário, a fim de proporcionar uma visão geral de sua organização.

\subsection{As microestruturas português-espanhol/espanhol- português}

A microestrutura que propomos para o dicionário está organizada da seguinte forma:

(1) termo-entrada: a UT figura como entrada em português ou em espanhol dependendo do dicionário. Os termos-entrada são organizados em ordem alfabética. 
(2) informação gramatical: essa informação se refere ao termo entrada e ao termo em relação de equivalência. Dita informação cumpre, sobretudo, a função de auxiliar o usuário na produção (ou tradução) de textos em língua estrangeira.

Isso se justifica porque em alguns casos existem diferenças, sobretudo com relação ao gênero, entre as duas línguas. As UTs alavancagem e apalancamiento, são exemplos de diferenças de gênero entre as duas línguas em questão.

\section{alavancagem s.f. $\quad$ apalancamiento s.m.}

(3) termo em relação de equivalência: julgamos pertinente apresentar a UT em relação de equivalência também nas entradas que se remetem a outras entradas com a definição. Tal procedimento auxilia o usuário no caso de necessitar apenas do termo equivalente por já conhecer seu significado em sua língua materna, como no exemplo abaixo.

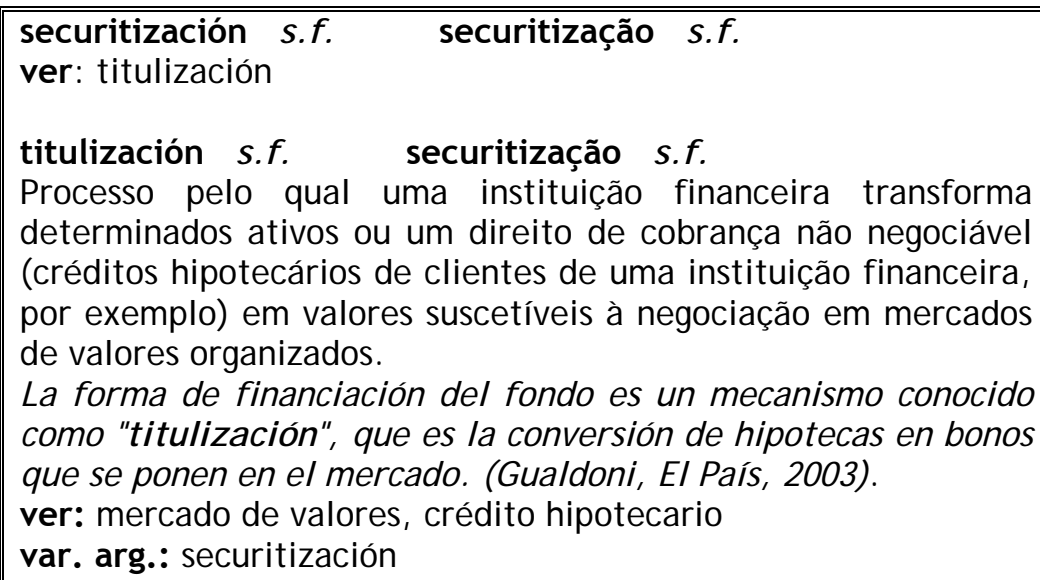

(4) definição: a definição terminológica é redigida na língua materna do usuário, isto é, no dicionário na direção português-espanhol, a definição é escrita em espanhol e, no dicionário na direção espanhol-português, a definição é apresentada em português. 
A opção por apresentar a definição terminológica na língua materna do usuário se justifica por diferentes razões:

(i) porque defendemos que um dicionário bilíngue tem como principal objetivo facilitar ao usuário acesso a uma informação que esteja em língua estrangeira. Assim, acreditamos que a melhor forma de facilitar esse acesso é por meio da língua materna, pois, se o usuário possui domínio suficiente da língua estrangeira para entender uma definição nessa língua, não necessitará de um dicionário bilíngue - poderá recorrer a um monolíngue;

(ii) porque no dicionário língua estrangeira-língua materna prioriza-se a função passiva, portanto, o usuário necessita de uma definição que 0 auxilie na compreensão de um texto em língua estrangeira. Seria contraditório apresenta-Ihe a definição também nessa língua.

No caso do dicionário para compreensão de textos, o usuário brasileiro encontra, no dicionário espanhol-português, o termo em relação de equivalência e as definições relativas à Economia Monetária da Espanha e da Argentina escritas no português do Brasil. 0 mesmo ocorre com o usuário espanhol ou argentino. Estes, por sua vez, encontram no dicionário portuguêsespanhol a definição do termo relativo à Economia Monetária do Brasil escrita em espanhol. ${ }^{3}$

Se o termo-entrada do dicionário português-espanhol for polissêmico, as diferentes acepções serão marcadas por números crescentes 1.[...]. 2.[...]. 3. [...].

3 Esclarecemos, no entanto, que optamos por utilizar na redação das definições em espanhol a variante peninsular da língua, em virtude, sobretudo, de parte da pesquisa ter se realizado na Espanha. 
alavancagem s.f. apalancamiento s.m.

1. Uso de activos o recursos ajenos para la formación del capital, con el objetivo de ampliar las ganancias de los inversores.

2. Adquisión de títulos o valores mobiliarios con recursos aj enos.

3.Operación de compraventa de activos, títulos y valores mobiliarios para liquidarse en el futuro.

No dicionário espanhol-português, se o termo-entrada se referir a significados diferentes entre Espanha e Argentina, encontra-se junto a ele 0 símbolo $(\neq)$ indicando que há diferença de significado entre os dois países. Nesse caso, cada acepção é indicada por uma flecha $(\rightarrow)$. Desse modo, não há entradas homônimas, mas sim verbetes polissêmicos.

\section{f agregado monetario s.m. agregado monetário s.m.}

Conj unto formado pela soma da moeda em circulação e o saldo de determinados passivos das instituições financeiras com alto grau de liquidez.

$\rightarrow$ No Eurosistema, o termo agregado monetário é composto pelo agregado monetario estrecho (M1) que é formado pela moeda em circulação e os depósitos à vista dos residentes na zona do euro em instituições financeiras localizadas nessa zona; o agregado monetario M2 que abrange o M1 mais os depósitos a prazo que não ultrapassem dois anos e os depósitos disponíveis com pré-aviso de até três meses; o agregado monetario amplio M3 que inclui o total formado pelo M2, as participações em fundos do mercado monetário e os valores diferentes de ações de até dois anos.

$\rightarrow \mathrm{Na}$ Argentina, o agregado monetário é também denominado ALP1 e é formado pelo agregado M3 mais os instrumentos a curto prazo emitidos pelas administrações públicas (títulos, Letras do Tesouro, etc). O agregado monetário na Argentina abrange, ainda, os ativos emitidos pelo sistema bancário (transferências de ativos privados e operações de seguro) e o crédito oficial (empréstitos). 0 M3, por sua vez, é formado pelo M2 mais os ativos em poder do público residente na Argentina emitido por instituições também residente no país (depósito a prazo, participaciones de activos, inversión temporal de activos privados y públicos, pagarés de crédito oficial, empréstitos del sistema bancario y activos líquidos en moneda extranjera). O M2 é formado pelo total do M1 mais os depósitos de poupança e o M1 é formado pela moeda em poder do público mais os depósitos à vista no sistema bancário.

Para a elaboração da definição, são observados os seguintes critérios:

- não são usadas expressões como: diz-se de, é, trata-se de, serve para, designar etc.

- a definição está pensada, sobretudo, para o usuário não especialista (aprendizes, mediadores linguísticos etc.); 
- as informações enciclopédicas, sempre que necessárias, aparecerão em forma de nota;

- em entradas cujo lema é uma UT monoléxica, o descritor será uma UT mais genérica e pertencente à mesma classe gramatical;

- em entradas cujo lema é uma UT poliléxica o descritor será, em geral, a base do sintagma;

- UTs que apresentem mais de um significado serão descritas sob uma mesma entrada, evitando-se, assim, entradas homonímicas;

- no caso de variação conceitual entre Espanha e Argentina as definições figurarão no mesmo verbete com indicação de qual acepção se refere a qual país.

Tanto no dicionário português-espanhol quanto no espanhol-português, quando houver relação parcial de equivalência entre as duas línguas, figura ao lado do termo-entrada o símbolo (气) e, em forma de Nota, os esclarecimentos necessários ao usuário.

플 mercado financeiro $\mathbf{s . m .}$ mercado financiero $\mathbf{s . m}$.

Conjunto de mercados de una Economía responsable por la captación de recursos entre inversionistas para la financiación de actividades productivas o generar ganancias para quien presta dinero. Ese proceso se regula por el Gobierno a través de un conjunto de instituciones entre las que se destaca el Banco Central.

Nota: El mercado financiero en Brasil se constituye por cuatro grandes mercados: mercado monetario; mercado de crédito; mercado de cambio y mercado de capitales que se subdividen en otros mercados.

(5) contexto: os contextos, extraídos de textos reais, servem para que 0 usuário possa observar o termo em uso e esclarecer, assim, possíveis dúvidas ao produzir ou traduzir um texto. 
mercado interbancário s.m. mercado interbancario s.m.

Instrumento del sistema financiero que refleja sus expectativas. En el mercado interbancario los precios son libres, sin la intervención del Banco Central. Es un mercado privado de los bancos y de los brokers que ejercen una función de "puente" entre los que compran y los que venden.

O mercado interbancário é privativo dos bancos e dos brokers. Caracteriza-se pela intermediação financeira a poupadores e vendedores de moeda de forma geral, atuando também como canal de distribuição de títulos, utilizados como lastro do dinheiro transacionado. (BRITO, 2005).

(6) formas variantes: essas UTs podem auxiliar o usuário na produção de textos em língua estrangeira, pois terão outras possibilidades de uso, evitando, entre outras coisas, as repetições que podem dificultar a compreensão do texto.

Referimo-nos, nesse caso, às variações internas a cada norma linguística. Evidentemente que, dadas as diferenças muitas vezes marcadas entre o espanhol europeu e o espanhol argentino, não seria conveniente por questões de uniformidade textual, usar, por exemplo, titulización e securitización em um mesmo texto.

ativo circulante s.m. activo circulante s.m.

Activo que posee liquidez inmediata, como: efectivo, saldos bancarios y valores que se puede convertirlos en efectivo inmediatamente. Son los activos más líquidos de una empresa, es decir, se puede convertirlos en dinero con gran facilidad.

Por exemplo, o estoque é um ativo circulante. Presumivelmente, o estoque será vendido a curto prazo. (PRESS, 2002).

Sin.: ativo de curto prazo; ativo realizável a curto prazo; ativo disponível.

(7) termos relacionados: essas unidades correspondem aos termos relacionados semanticamente com o lema como, por exemplo, hiperônimos e hipônimos. A presença dessas UTs tem como objetivo proporcionar ao usuário uma maior compreensão sobre as relações de significado existentes na área que está aprendendo ou na qual desenvolve suas atividades profissionais: 
\begin{tabular}{|lll}
\hline risco de crédito & s.m. & riesgo de crédito \\
s.m.
\end{tabular}

Posibilidad de impago de una deuda o de sus rentabilidades en la fecha de vencimiento. Se caracteriza, en general, como el principal riesgo que los bancos afrentan.

Ver: risco-país, risco soberano, risco de liquidação

(8) nota: nesse espaço se proporciona ao usuário outras informações que possam elucidar possíveis dúvidas como, por exemplo, questões relativas a UTs usadas na variedade argentina frente ao espanhol europeu. Além disso, apresenta-se também nesse espaço informações de cunho enciclopédico que, muitas vezes, contribuem a uma compreensão mais eficiente da UTs em questão, sobretudo no caso dos aprendizes ou dos profissionais de outras áreas (tradutores, revisores, secretários executivos etc.) que não são especialistas em Economia.

\section{risco-país s.m. riesgo país $\mathbf{s . m}$.}

Riesgo que se relaciona a la política económica del país y a los cambios que ésta puede sufrir. Ese tipo de riesgo se refiere a un concepto más amplio que el risco-soberano pues incluye, además del risco-soberano, los activos financieros del país.

O risco-país é o principal termômetro para medir a desconfiança dos investidores sobre um país (http:// dinheironet.uol.com.br)

Nota: El índice del risco-país se lo calcula las agencias de clasificación de riesgos y bancos de inversiones a través de un índice que se denomina Emerging Markets Bond Index Plus (EMBI+) y sirve para medir los peligros que un país representa al inversionista extranjero.[...]. Ese índice mide la diferencia, en centésimos de puntos porcentuales, entre la media de los intereses pagos por los títulos de la deuda de determinado país y los intereses de los títulos del Tesoro de Ios EUA, considerados virtualmente de riesgo cero. 


\section{Considerações Finais}

Nosso objetivo primordial nesse trabalho foi 0 de descrever a metodologia usada na elaboração de uma proposta de dicionário terminológico bilíngue. Dito dicionário deverá adequar-se aos falantes da língua de partida e aos falantes da língua de chegada e, ainda, contemplar as variedades linguísticas peninsular e argentina da língua espanhola bem como 0 português brasileiro.

Usamos, para isso, os pressupostos teóricos e metodológicos da Teoria Comunicativa da Terminologia. Essa teoria defende a necessidade de se refletir sobre o possível usuário do dicionário que se pretende elaborar e a(s) função(ões) que a obra deve cumprir. 0 usuário e suas necessidades linguísticas caracterizam-se, assim, como o início do caminho a se percorrer ao logo do labor terminográfico.

A partir das reflexões teórico-metodológicas que apresentamos e, com base no perfil do possível usuário, pudemos elaborar uma proposta de dicionário bilíngue considerando os diferentes casos de variação no uso especializado do PB e do espanhol.

A estrutura proposta para o dicionário caracteriza-se como a aplicação do Princípio de Adequação defendido pela TCT na elaboração de um dicionário terminológico. 0 modelo de dicionário proposto parte de um fator básico e fundamental: o usuário potencial da obra. Esse dicionário é pensado a dois tipos de usuários, o falante de português e o falante de espanhol.

Entretanto, trata-se de um modelo flexível que, por partir das necessidades de seu possível usuário, poderá ser adaptado a outros usuários, como, por exemplo, poderá tornar-se um dicionário bilíngue destinado somente para o falante de português, ou um dicionário pensado somente para o falante de espanhol. A estrutura que elaboramos, considerando o usuário e a variação, pode ainda ser aplicada à elaboração de um dicionário voltado para o ensino de línguas estrangeiras, isto é, poderíamos pensar em um 
dicionário destinado ao brasileiro aprendiz de espanhol ou ao falante de espanhol aprendiz de português.

Assim, a pesquisa descrita nesse artigo cumpre um objetivo teórico e um prático. O objetivo teórico se refere às reflexões e propostas que desenvolvemos e que poderão, em algum momento, dar margem a novos questionamentos e reflexões, originando novas pesquisas. 0 objetivo prático está relacionado à proposta de dicionário que, por sua vez, também poderá vir a ser um instrumento de reflexões sobre os estudos em Terminologia e Terminografia no Brasil.

\section{Agradecimento}

À Profa. Dra. Maria Tereza Camargo Biderman (in memoriam)

\section{Referências bibliográficas}

BAleeiro, A. Uma Introdução à ciência das finanças. Rio de J aneiro: Forense, 2002.

Biderman, M. T. C. Dicionário de Termos Financeiro e Bancários. São Paulo: Disal, 2006.

- Teoria Linguística (teoria lexical e linguística computacional). São Paulo: Martins Fontes, 2001.

- Corpus de textos bancários e financeiros. Universidade Estadual Paulista Julio de Mesquita Filho - UNESP. Araraquara, 2003. [Não publicado].

BRITo, O. Mercado Financeiro. São Paulo: Saraiva, 2005.

CABRÉ, M. T. La terminología: Representación y comunicación. Elementos para una teoría de base comunicativa y otros artículos. Barcelona: Institut Universitari de Lingüística Aplicada, Universitat Pompeu Fabra, 1999.

CABRÉ, M. T., Feliu, J. La Terminología científico-técnica: reconocimiento, análisis y extracción de información formal y semántica. Barcelona: Universitat Pompeu Fabra. Institut Universitari de Lingüística Aplicada, 2001. 
Cano, W. M. Teoria e Práxis de um Dicionário Escolar de Ciências. Tese (Doutorado em Linguística e Língua Portuguesa). Universidade Estadual Paulista. Faculdade de Ciências e Letras. Araraquara, 2001.

ForTUNA, E. Mercado financeiro: produtos e serviços. 15. ed. Rio de J aneiro: Qualitymark, 2002.

Gelpi ARRoyo, C. Mesures d'avaluació lexicogràfica de diccionaris bilingües. Tesis doctoral. Programa de doctorat: Variació en el Llenguatge. Universitat de Barcelona, 1997. Barcelona: Institut Universitari de Lingüística Aplicada - Universitat Pompeu Fabra, 2003.

Granato, L. Protección del inversor extranjero y arbitraje internacional en los Tratados Bilaterales de Inversión. Facultad de Derecho y Ciencias Sociales. Universidad de Belgrano, Argentina. 2005. Disponível em: বhttp:/ / www. eumed. net/ libros/2005/ lg/ >. (13/ 10/ 2005).

HAENSCH, G. et al. La lexicografía: de la Lingüística Teórica a la Lexicografía Práctica. Madrid: Gredos, 1982.

LamelRA, V. Mercado de Capitais. Rio de J aneiro: Forense, 2001.

LoPES, J. do C.; RossetTI, J. P. Economia Monetária. 6.ed. São Paulo: Atlas, 1996.

LORENTE, M. Teoría e innovación en terminografía: la definición terminográfica. In. CABRÉ, M. T., FeLIU, J. La Terminología científicotécnica: reconocimiento, análisis y extracción de información formal y semántica. Barcelona: Universitat Pompeu Fabra. Institut Universitari de Lingüística Aplicada, 2001.

NADIN, O. L. Corpus de textos bancários e financeiros em língua espanhola Espanha e Argentina. Faculdade de Ciências e Letras. Universidade Estadual Paulista Julio de Mesquita Filho - UNESP. Araraquara, 2003. [Não publicado].

OdONNE, C. N. Mercados Emergentes y Crisis Financiera Internacional. Disponível em: বhtml:// www. eumed. net/cursecon/libreria/ >. 2004. (20/01/2005).

Rezende, F. A. Finanças Públicas. 2.ed. São Paulo: Atlas, 2001.

SARDinha, T. B. Linguística de Corpus. São Paulo: Manole, 2004.

. T. B. Linguística de Corpus: histórico e problemática. DELTA, vol. 16, № 2. São Paulo, 2000: 323-367.

SINCLAIR, J. Corpus, Concordance, Collocation. Oxford: Oxford University Press, 1991.

VIRGILE, A. ¿Ahorrar para acumular o para financiar la crisis? Una aproximación a sesenta y cinco años de ahorro privado en Argentina. Disponível em: \http:// www. eumed. net/ cursecon/libreria/ >. 2004. (20/01/2005). 


\section{Anexo}

\section{Sites fontes dos textos que compõem os corpora}

\begin{tabular}{|c|c|}
\hline Português & Espanhol \\
\hline http:// dinheironet.uol.com. br & http:// www. cambiocultural.com. ar/ investigacion/ andreiul. \\
\hline http:// galeriadeinvestimentos. unibanco.com. br & htm. \\
\hline http:// galeriadeinvestimentos. unibanco.com. br & http:// www.alzasybajas. com.ar \\
\hline http:// gwnit. microlink. com. br/ jjsfilho/ / fundos. htm & http:// www.bcra.gov.ar \\
\hline http:// portalexame. abril.uol.com.br & http:// www.hipotecario.com.ar/ \\
\hline http:// redeglobo5. globo.com/ joelmirbeting/ noticias & http:// www. fundacioncredicoop.com. ar/ \\
\hline http:// www. investnews. net/ dredacao & http:// www. bcba.sba.com. ar/ \\
\hline http:// www. primeiraleitura.com.br & http:// www. matba.com.ar/ \\
\hline http:// www.puc-rio.br/ & http:// ciberconta.unizar.es \\
\hline http:// www. risktech. com. br & http:// www. bcr.com.ar/ \\
\hline http:// www. srrating.com.br & http:// www. monografias. com/ trabaj os4/ intecon/ intecon.s \\
\hline http:// www.uol.com.br/ economia & (2) \\
\hline IEA - Instituto de Economia Agrícola. & www. bapro.com.ar \\
\hline http:// www. iea.sp. gov. br/ out/ index. php & www.aba.com.ar \\
\hline ww. gazetamercantil.com. br & www. bolsar.com \\
\hline ww. shoji.com.br & www.bce.es \\
\hline www. abamec.com. br & www.bde.es \\
\hline www. abrapp.org. br & www.bbva.es \\
\hline www. abrapp. org. br/ portal & www. bancodevalencia.es \\
\hline www. abrasca.com. br & www. bancosantander.es \\
\hline www. agrolink. com. br & www.ibercaja.es \\
\hline www. agrolink. com. br & www.clarin.com \\
\hline www. agrolink. com. br & www. mercado.com. ar \\
\hline www. animec.com. br & www.elpais.es \\
\hline www. banespa.com. br & www.eumed.net \\
\hline www. bankboston. com. br & www.americaeconomica.com \\
\hline www.bb.com. br & www. fortuna. uolsinectis. com. ar/ \\
\hline www.bcb.gov.br & www.bde.es \\
\hline www. bienasbm. ufba.br & www.eco.uba.ar/ \\
\hline www.bmf.com. br & www. monografias. com/ trabaj os4/ intecon/ intecon. shtml \\
\hline www. bovespa.com. br/pdf/termo. pdf & www.depeco.econo.unbp. edu.ar \\
\hline www. bungeprev.com. br & www. mecon.gov.ar. \\
\hline www.camara.gov.br & www.cnv.ar \\
\hline www. capitalderisco.gov.br & www.cnmv.es \\
\hline www. capitalderisco.gov.br & www. eumed. net/ cursecon/ cursos/ mmff/ clases. htm \\
\hline www.cef.gov.br & www. portaldeabogados. com. ar/ codigos/ cheques \\
\hline www. desafios. org.br & www.uclm.es/ profesorado/ rmarban \\
\hline www. estadao.com. br & www. uif.gov.ar/ \\
\hline www. estadao.com. br/ economia/ noticias & www. auladeeconomia.com \\
\hline www. febraban. org.br & www.e-potecatirio.com. ar \\
\hline www.fgvsp.br & www.uclm.es \\
\hline www.fgvsp.br & www.dinero.com.es \\
\hline www.ime.usp.br & www. aulafacil.com \\
\hline www.ime.usp.br & www.emp.uva.es \\
\hline www.ipea.gov.br & www. neuquen.gov.br \\
\hline www.joelmirbeting.com.br/ & www. mervalweb.com. ar \\
\hline www.mre.gov.br & www.depeco.econo.unbp.edu. ar \\
\hline www.pde.com.br & www.eco.uba.ar \\
\hline www.pde.com.br & www.econlink. com. ar \\
\hline www. risktech.com. br/ PDFs/ hedge. pdf & www. mecon.gov.ar \\
\hline www.stm. fazenda.gov. br & www. monografia.com \\
\hline www.topecon. hpg. ig. com. br & \\
\hline www.unb.br & \\
\hline www.unioeste.br & \\
\hline www. valor.com. br & \\
\hline
\end{tabular}

